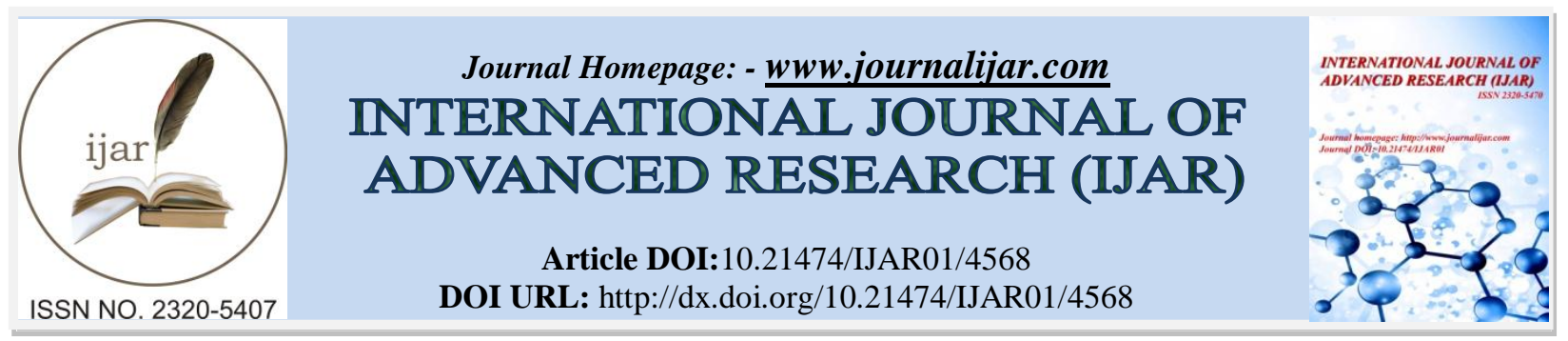

RESEARCH ARTICLE

\title{
ON rgwalc-SEPARATION AXIOMS IN TOPOLOGICAL SPACES.
}

\section{R. S. Wali ${ }^{1}$ and Vijayalaxmi R. Patil ${ }^{2}$}

1. Department of MathematicsBhandari and Rathi College, Guledagudd, Karnataka, India.

2. Department of MathematicsRani Channamma University Belagavi, Karnataka, India.

\section{Manuscript Info}

Manuscript History

Received: 22 April 2017

Final Accepted: 24 May 2017

Published: June 2017

\section{Abstract}

The aim of this paper is to introduce and study two new classes of spaces, namely rgw $\alpha$ lc- $\tau_{0}$, rgw $\alpha$ lc- $\tau_{1}$, rgw $\alpha$ lc- $\tau_{2}$, rgw $\alpha$ lc-regular and rgwolc-normal spaces and obtained their properties by utilizing rgwalc-closed sets. Also we will present some characterizations of these spaces.

Key words:-

rgw $\alpha$ lc-closed set, RGW $\alpha \mathrm{LC}$ -

continuous function, RGW $\alpha \mathrm{LC}$ -

irresolute, rgw $\alpha \mathrm{lc}-\tau_{0}$ space, rgw $\alpha \mathrm{lc}-\tau_{1}$

space, rgw $\alpha$ lc- $\tau_{2}$ space,rgw $\alpha$ lc-regular

space and rgwolc-normal space.

Copy Right, IJAR, 2017,. All rights reserved.

\section{Introduction:-}

Munshi [1], introduced g-regular and g- normal spaces using g-closed sets of Levine [4]. Maheshwari and Prasad [7] introduced the new class of spaces called s-normal spaces using semi-open sets. It was further studied by Noiri and Popa[10],Dorsett[2] and Arya[8]. Later, Benchalli et al [9] and Shik John[3] studied the concept of $\mathrm{g}^{*}-\mathrm{pre}$ regular, $\mathrm{g}^{*}$ - pre normal and w-normal, w-regular spaces in topological spaces. Recently, Wali et al [5,6] introduced and studied the properties of rgw $\alpha$ lc-closed sets and RGW $\alpha$ LC-continuous andRGW $\alpha \mathrm{LC}$-irresolute maps.

\section{Preliminaries:-}

Throughout this paper $(\mathrm{X}, \tau),(\mathrm{Y}, \tau)$ (or simply $\mathrm{X}, \mathrm{Y})$ denote topological spaces on which no separation axioms are assumed unless explicitly stated. For a subset $A$ of a space $X$ the closure, interior and r $\alpha-$ closure of $A$ with respect to $\tau$ are denoted by $\operatorname{cl}(\mathrm{A})$, int(A) and $\operatorname{racl}(\mathrm{A})$ respectively

Definition 2.1: A subset $A$ of a topological space $X$ is called a

(1)semi-open set [9] if $\mathrm{A} \subseteq \operatorname{cl}(\operatorname{int}(\mathrm{A}))$.

(2)w-closed set [3] if $\operatorname{cl}(\mathrm{A}) \subseteq \mathrm{U}$ whenever $\mathrm{A} \subseteq \mathrm{U}$ and $\mathrm{U}$ is semi-open in $\mathrm{X}$.

(3) g-closed set [4] if $\operatorname{cl}(\mathrm{A}) \subseteq \mathrm{U}$ whenever $\mathrm{A} \subseteq \mathrm{U}$ and $\mathrm{U}$ is open in $\mathrm{X}$.

Definition 2.2: A topological space $X$ is called

i) a $\alpha-\tau_{0}[11]$ if for each pair of distinct points $\mathrm{x}, \mathrm{y}$ of $\mathrm{X}$, there exists a $\alpha$-open sets $\mathrm{G}$ in $\mathrm{X}$ containing one of them and not the other.

ii) a $\alpha-\tau_{1}[11]$ if for each pair of distinct points $\mathrm{x}$, $\mathrm{y}$ of $\mathrm{X}$, there exists two $\alpha$-open sets $\mathrm{G} 1, \mathrm{G} 2$ in $\mathrm{X}$ such that $\mathrm{x} \in \mathrm{G} 1$ , $\mathrm{y} \notin \mathrm{G} 1$, and $\mathrm{y} \in \mathrm{G} 2$, $\mathrm{x} \notin \mathrm{G} 2$.

Corresponding Author:-R. S. Wali.

Address:-Department of MathematicsBhandari and Rathi College, Guledagudd, Karnataka, India. 
iii) a $\alpha-\tau_{2}$ [11] ( $\alpha-$ Hausdorff) if for each pair of distinct points $\mathrm{x}, \mathrm{y}$ of $\mathrm{X}$ there exists distinct $\alpha-$ open sets $\mathrm{H} 1$ and $\mathrm{H} 2$ such that $\mathrm{H} 1$ containing $\mathrm{x}$ but not $\mathrm{y}$ and $\mathrm{H} 2$ containing $\mathrm{y}$ but not $\mathrm{x}$.

Definition 2.3: A topological space $X$ is said to be a

(1)g-regular[10], if for each $\mathrm{g}$-closed set $\mathrm{F}$ of $\mathrm{X}$ and each point $\mathrm{x} \notin \mathrm{F}$, there exists disjoint open sets $\mathrm{U}$ and $\mathrm{V}$ such that $\mathrm{F} \subseteq \mathrm{U}$ and $\mathrm{x} \in \mathrm{V}$.

(2) $\alpha-$-regular [4], if for each closed set $F$ of $X$ and each point $x \notin F$, there exists disjoint $\alpha$-open sets $U$ and $V$ such that $\mathrm{F} \subseteq \mathrm{V}$ and $\mathrm{x} \in \mathrm{U}$.

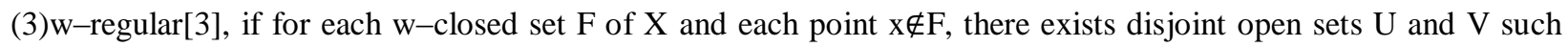
that $\mathrm{F} \subseteq \mathrm{U}$ and $\mathrm{x} \in \mathrm{V}$.

Definition 2.4: A topological space $X$ is said to be a

(1) g-normal [10], if for any pair of disjoint $\mathrm{g}$-closed sets $\mathrm{A}$ and $\mathrm{B}$, there exists disjoint open sets $\mathrm{U}$ and $\mathrm{V}$ such that $\mathrm{A} \subseteq \mathrm{U}$ and $\mathrm{B} \subseteq \mathrm{V}$.

(2) $\alpha$-normal [4], if for any pair of disjoint closed sets A and B, there exists disjoint $\alpha$-open sets $\mathrm{U}$ and $\mathrm{V}$ such that $\mathrm{A} \subseteq \mathrm{U}$ and $\mathrm{B} \subseteq \mathrm{V}$.

(3) w-normal [3], if for any pair of disjoint w-closed sets A and B, there exists disjoint open sets $\mathrm{U}$ and $\mathrm{V}$ such that $\mathrm{A} \subseteq \mathrm{U}$ and $\mathrm{B} \subseteq \mathrm{V}$.

Definition 2.5: A subset A of a topological space $X$ is called a

(i)regular generalized weakly $\alpha$-locally closed [5] (briefly rgw $\alpha$ lc- closed) if $\mathrm{A}=\mathrm{U} \cap \mathrm{F}$ where $\mathrm{U}$ is $\mathrm{rgw} \alpha$-open in (X, $\tau)$ and $\mathrm{F}$ is $\operatorname{rgw} \alpha$-closed in $(\mathrm{X}, \tau)$.

(ii)regular generalized weakly $\alpha$-locally open [5] (briefly rgw $\alpha$ lc- open) if $\mathrm{A}^{\mathrm{c}}$ is $\operatorname{rgw} \alpha$-locally closed.

Definition 2.6: [5] A topological space $X$ is called $\tau$ rgw $\alpha$ lc-space if every rgw $\alpha$ lc-closed set in it is closed set.

Definition 2.7: A function $\mathrm{f}: \mathrm{X} \rightarrow \mathrm{Y}$ is called

(1) RGW $\alpha$ LC-continuous [6] (resp. w-continuous [12]) if $\mathrm{f}^{-1}(\mathrm{~F})$ is RGW $\alpha$ LC-closed (resp. w-closed) set in $\mathrm{X}$ for every closed set $\mathrm{F}$ of $\mathrm{Y}$.

(2) RGW $\alpha$ LC -irresolute [6] (resp. w-irresolute [12]) if $\mathrm{f}^{-1}$ (F) is RGW $\alpha$ LC-closed (resp. W-closed set in X for every RGW $\alpha \mathrm{LC}$-closed (resp. w- closed) set F of Y.

rgwalc- $\tau_{\mathrm{k}}$ Space $(\mathrm{k}=0,1,2)$.

Definition 3.1: A topological space $X$ is called

i) a rgwalc $-\tau_{0}$ if for each pair of distinct points $\mathrm{x}$, $\mathrm{y}$ of $\mathrm{X}$, there exists a rgwalc-open set $\mathrm{G}$ in $\mathrm{X}$ containing one of them and not the other.

ii) a rgwalc- $\tau_{1}$ if for each pair of distinct points $\mathrm{x}$, $\mathrm{y}$ of $\mathrm{X}$, there exists two rgwalc- open sets $\mathrm{G} 1, \mathrm{G} 2 \mathrm{in} \mathrm{X}$ such that $\mathrm{x} \in \mathrm{G} 1, \mathrm{y} \notin \mathrm{G} 1$, and $\mathrm{y} \in \mathrm{G} 2, \mathrm{x} \notin \mathrm{G} 2$.

iii) a rgwalc- $\tau_{2}($ rgwalc- Hausdorff) if for each pair of distinct points $\mathrm{x}$, y of $\mathrm{X}$ there exists distinct rgwalc-open sets $\mathrm{H}_{1}$ and $\mathrm{H}_{2}$ such that $\mathrm{H}_{1}$ containing $\mathrm{x}$ but not $\mathrm{y}$ and $\mathrm{H} 2$ containing $\mathrm{y}$ but not $\mathrm{x}$.

\section{Theorem 3.2:}

(i) Every $\tau_{0}$ space is rgw $\alpha$ lc $-\tau_{0}$ space.

(ii) Every $\tau_{1}$ space is rgw $\alpha \mathrm{lc}-\tau_{0}$ space.

(iii) Every $\tau_{1}$ space is rgw $\alpha$ lc $-\tau_{1}$ space.

(iv) Every $\tau_{2}$ space is rgw $\alpha \mathrm{lc}-\tau_{2}$ space.

(v) Every rgw $\alpha \mathrm{lc}-\tau_{1}$ space is rgw $\alpha \mathrm{lc}-\tau_{0}$ space.

(vi) Every rgw $\alpha \mathrm{lc}-\tau_{2}$ space is rgw $\alpha \mathrm{lc}-\tau_{1}$ space.

Proof: Straight forward.

The converse of the theorem need not be true as in the examples.

Example 3.3: Let $\mathrm{X}=\{\mathrm{a}, \mathrm{b}, \mathrm{c}, \mathrm{d}\}$ and $\tau=\{\mathrm{X}, \Phi,\{\mathrm{a}\},\{\mathrm{a}, \mathrm{b}\}\}$. Then $\operatorname{rgw} \alpha \operatorname{lcC}(\mathrm{X})=\operatorname{rgw} \alpha \operatorname{lcO}(\mathrm{X})=\mathrm{P}(\mathrm{X})$. Here $(\mathrm{X}, \tau)$ is $\operatorname{rgw} \alpha \mathrm{lc}-\tau_{0}$ and rgwalc- $\tau_{1}$ space but not $\tau_{0}$ space and not $\tau_{1}$ space. 
Example 3.4: Let $\mathrm{X}=\{\mathrm{a}, \mathrm{b}, \mathrm{c}\}$ and $\tau=\{\mathrm{X}, \Phi,\{\mathrm{a}\},\{\mathrm{b}\},\{\mathrm{a}, \mathrm{b}\}\}$. Then $\operatorname{rgw} \alpha \operatorname{lc} C(\mathrm{X})=\operatorname{rgw\alpha } \operatorname{lcO}(\mathrm{X})=\mathrm{P}(\mathrm{X})$. Here $(\mathrm{X}, \tau)$ is rgw $\alpha$ lc $-\tau_{2}$ space but not $\tau_{2}$ space.

\section{Theorem 3.5:}

(i) Every $\alpha-\tau_{0}$ space is rgw $\alpha$ lc $-\tau_{0}$ space.

(ii) Every $\alpha-\tau_{1}$ space is $\operatorname{rgw} \alpha \mathrm{lc}-\tau_{0}$ pace.

(iii) Every $\alpha-\tau_{1}$ space is rgw $\alpha$ lc $-\tau_{1}$ space.

(iv) Every $\alpha-\tau_{2}$ space is rgw $\alpha$ lc $-\tau_{2}$ space.

Proof: i) For each pair of distinct points $\mathrm{x}$, y of X. Since $\alpha-\tau_{0}$ space, there exists a $\alpha$-open sets $\mathrm{G}$ in X containing one of them and not the other. But every $\alpha$-open is rgw $\alpha$ lc- open then there exists a $\alpha$-open sets $\mathrm{G}$ in X containing one of them and not the other. Therefore rgw $\alpha$ lc $-\tau_{0}$ space.

ii) Since $\alpha-\tau_{1}$ space, but every $\alpha-\tau_{1}$ space is $\alpha-\tau_{0}$ space and also from Theorem 5.5(i). Therefore rgw $\alpha$ lc $-\tau_{0}$ space. iii) and (iv) similarly we can prove.

Theorem 3.6: Let $\mathrm{X}$ be a topological space and $\mathrm{Y}$ is an rgwalc- $\tau_{0}$ space. If $\mathrm{f}: \mathrm{X} \rightarrow \mathrm{Y}$ is injective and rgw $\alpha$ lcirresolute then $\mathrm{X}$ is rgwolc $-\tau_{0}$ space.

Proof: Suppose $x, y \in X$ such that $x \neq y$. Since $f$ is injective then $f(x) \neq f(y)$. Since $Y$ is rgwalc $-\tau_{0}$ space then there exists a rgwolc-open sets $\mathrm{U}$ in $\mathrm{Y}$ such that $\mathrm{f}(\mathrm{x}) \in \mathrm{U}, \mathrm{f}(\mathrm{y}) \mathrm{U}$ or there exists a rgwalc-open sets $\mathrm{V}$ in $\mathrm{Y}$ such that $\mathrm{f}(\mathrm{y}) \in \mathrm{V}, \mathrm{f}(\mathrm{x}) \mathrm{V}$ with $\mathrm{f}(\mathrm{x}) \neq \mathrm{f}(\mathrm{y})$. Since $\mathrm{f}$ is rgwalc- irresolute then $\mathrm{f}^{-1}(\mathrm{U})$ is a rgwolc-open sets in $\mathrm{X}$ such that $\mathrm{x} \in \mathrm{f}^{-}$ ${ }^{1}(\mathrm{U}), \mathrm{y} \mathrm{f}^{-1}(\mathrm{U})$ or $\mathrm{f}^{-1}(\mathrm{~V})$ is a rgwalc-open sets in $\mathrm{X}$ such that $\mathrm{y} \in \mathrm{f}^{-1}(\mathrm{~V}), \mathrm{x} \mathrm{f}^{-1}(\mathrm{~V})$. Hence $\mathrm{X}$ is rgw $\alpha \mathrm{lc}-\tau_{0}$ space.

Theorem 3.7: Let $\mathrm{X}$ be a topological space and $\mathrm{Y}$ is an rgwalc- $\tau_{2}$ space. If $\mathrm{f}: \mathrm{X} \rightarrow \mathrm{Y}$ is injective and rgwalcirresolute then $\mathrm{X}$ is rgw $\alpha \mathrm{lc}-\tau_{2}$ space.

Proof: Suppose $x, y \in X$ such that $x \neq y$. Since $f$ is injective then $f(x) \neq f(y)$. Since $Y$ is rgwalc- $\tau_{2}$ space then there are two rgwalc-open sets $U$ and $V$ in $Y$ such that $f(x) \in U, f(y) \in V$ and $U \cap V=\Phi$. Since $f$ is rgwalc- irresolute then $f^{-}$ ${ }^{1}(U), f^{-1}(V)$ are two rgw $\alpha$ lc- open sets in $X, x \in f^{-1}(U), y \in f^{-1}(V), f^{-1}(U) \cap f^{-1}(V)=\Phi$. Hence $X$ is rgwalc- $\tau_{2}$ space.

Theorem 3.8: Let $\mathrm{X}$ be a topological space and $\mathrm{Y}$ is an $\operatorname{rgw} \alpha \mathrm{lc}-\tau_{1}$ space. If $\mathrm{f}: \mathrm{X} \rightarrow \mathrm{Y}$ is injective and rgwalcirresolute then $\mathrm{X}$ is rgwalc- $\tau_{1}$ space.

Proof: Similarly to Theorem 3.7.

Theorem 3.9: Let $\mathrm{X}$ be a topological space and $\mathrm{Y}$ is an $\tau_{2}$ space. If $\mathrm{f}: \mathrm{X} \rightarrow \mathrm{Y}$ is injective and rgwalc- continuous then $\mathrm{X}$ is rgwolc- $\tau_{2}$ space.

Proof: Suppose $\mathrm{x}, \mathrm{y} \in \mathrm{X}$ such that $\mathrm{x} \neq \mathrm{y}$. Since $\mathrm{f}$ is injective, then $\mathrm{f}(\mathrm{x}) \neq \mathrm{f}(\mathrm{y})$. Since $\mathrm{Y}$ is an $\tau_{2}$ space, then there are two open sets $U$ and $V$ in $Y$ such that $f(x) \in U, f(y) \in V$ and $U \cap V=\Phi$. Since $f$ is $\operatorname{rgw} \alpha$ lc- continuous then $f^{-1}(U), f^{-1}(V)$ are two rgwalc- open sets in $X$. Then $x \in f^{-1}(U), y \in f^{-1}(V), f^{-1}(U) \cap f^{-1}(V)=\Phi$. Hence $X$ is rgwolc- $\tau_{2}$ space.

Theorem 3.10: $(X, \tau)$ is $\operatorname{rgw} \alpha \mathrm{lc}-\tau_{0}$ space if and only if for each pair of distinct $\mathrm{x}, \mathrm{y}$ of $\mathrm{X}, \operatorname{rgw} \alpha \operatorname{lc}-\mathrm{cl}(\{\mathrm{x}\}) \neq \operatorname{rgw} \alpha \mathrm{lc}-$ $\operatorname{cl}(\{y\})$.

Proof: Let $(\mathrm{X}, \tau)$ be a $\operatorname{rgw} \alpha \mathrm{lc}-\tau_{0}$ space. Let $\mathrm{x}, \mathrm{y} \in \mathrm{X}$ such that $\mathrm{x} \neq \mathrm{y}$, then there exists a rgw $\alpha \mathrm{lc}-$ open set $\mathrm{V}$ containing one of the points but not the other, say $\mathrm{x} \in \mathrm{V}$ and $\mathrm{y} \notin \mathrm{V}$. Then $\mathrm{V}^{\mathrm{c}}$ is a rgwalc-closed containing $\mathrm{y}$ but not $\mathrm{x}$. But $\operatorname{rgw} \alpha \mathrm{lc}-\mathrm{cl}(\{\mathrm{y}\})$ is the smallest rgwalc-closed set containing $\mathrm{y}$. Therefore $\operatorname{rgw} \alpha \mathrm{lc}-\mathrm{cl}(\{\mathrm{y}\}) \subset \mathrm{V}^{\mathrm{c}}$ and hence $\mathrm{x} \notin \operatorname{rgw} \alpha \mathrm{lc}-\operatorname{cl}(\{\mathrm{y}\})$. Thus $\operatorname{rgw} \alpha \mathrm{lc}-\mathrm{cl}(\{\mathrm{x}\}) \neq \operatorname{rgw} \alpha \mathrm{lc}-\mathrm{cl}(\{\mathrm{y}\})$.

Conversely, suppose $\mathrm{x}, \mathrm{y} \in \mathrm{X}, \mathrm{x} \neq \mathrm{y}$ and $\operatorname{rgw\alpha } \alpha \mathrm{c}-\mathrm{cl}(\{\mathrm{x}\}) \neq \operatorname{rgw\alpha lc}-\mathrm{cl}(\{\mathrm{y}\})$. Let $\mathrm{z} \in \mathrm{X}$ such that $\mathrm{z} \in \operatorname{rgw} \alpha \mathrm{lc}-\mathrm{cl}(\{\mathrm{x}\})$ but $\mathrm{z} \notin \operatorname{rgw} \alpha \mathrm{lc}-\mathrm{cl}(\{\mathrm{y}\})$. If $\mathrm{x} \in \operatorname{rgw} \alpha \mathrm{lc}-\mathrm{cl}(\{\mathrm{y}\})$ then $\operatorname{rgw} \alpha \mathrm{lc}-\mathrm{cl}(\{\mathrm{x}\}) \subset \operatorname{rgw} \alpha \mathrm{lc}-\mathrm{cl}(\{\mathrm{y}\})$ and hence $\mathrm{z} \in \operatorname{rgw} \alpha \mathrm{lc}-\mathrm{cl}(\{\mathrm{y}\})$. This is a contradiction. Therefore $\mathrm{x} \notin \operatorname{rgw} \alpha \operatorname{lc}-\mathrm{cl}(\{\mathrm{y}\})$. That is $\mathrm{x} \in(\operatorname{rgw} \alpha \mathrm{lc}-\mathrm{cl}(\mathrm{y}))^{\mathrm{c}}$. Therefore $(\operatorname{rgw} \alpha \mathrm{lc}-\mathrm{cl}(\{\mathrm{y}\}))^{\mathrm{c}}$ is a rgwalc- open set containing $\mathrm{x}$ but not $\mathrm{y}$. Hence $(\mathrm{X}, \tau)$ is rgw $\alpha \mathrm{lc}-\tau_{0}$ space.

Theorem 3.11: A topological space $X$ is rgwalc- $\tau_{1}$ space if and only if for every $\mathrm{x} \in \mathrm{X}$ singleton $\{\mathrm{x}\}$ is $\operatorname{rgw} \alpha \mathrm{lc}-$ closed set in $\mathrm{X}$.

Proof: Let $X$ be rgwalc- $\tau_{1}$ space and let $x \in X$, to prove that $\{x\}$ is rgwalc-closed set. We will prove $X-\{x\}$ is rgwalc- open set in $\mathrm{X}$. Let $\mathrm{y} \in \mathrm{X}-\{\mathrm{X}\}$, implies $\mathrm{X} \neq \mathrm{y} \in$ and since $\mathrm{X}$ is rgw $\alpha$ lc- $\tau_{1}$ space then their exit two rgw $\alpha$ lcopen sets $\mathrm{G} 1, \mathrm{G} 2$ such that $\mathrm{x} \notin \mathrm{G} 1, \mathrm{y} \in \mathrm{G} 2 \subseteq X-\{x\}$. Since $\mathrm{y} \in \mathrm{G} 2 \subseteq X-\{x\}$ then $X-\{x\}$ is rgwalc- open set. Hence $\{\mathrm{x}\}$ is rgwalc-closed set. 
Conversely, Let $\mathrm{x} \neq \mathrm{y} \in \mathrm{X}$ then $\{\mathrm{x}\},\{\mathrm{y}\}$ are rgwalc- closed sets. That is $\mathrm{X}-\{\mathrm{x}\}$ is rgwalc-open set. Clearly, $\mathrm{x \notin X}-$ $\{x\}$ and $y \in X-\{x\}$.Similarly $X-\{y\}$ is rgw $\alpha$ lc- open set, $y \notin X-\{y\}$ and $x \in X-\{y\}$. Hence $X$ is rgw $\alpha$ lc $-\tau_{1}$ space.

Theorem 3.12: For a topological space $(X, \tau)$, the following are equivalent

(i) $(\mathrm{X}, \tau)$ is rgwalc- $\tau_{2}$ space.

(ii) If $\mathrm{x} \in \mathrm{X}$, then for each $\mathrm{y} \neq \mathrm{x}$, there is a rgw $\alpha \mathrm{lc}-$ open set $\mathrm{U}$ containing $\mathrm{x}$ such that $\mathrm{y} \notin \operatorname{rgw} \alpha \mathrm{lc}-\mathrm{cl}(\mathrm{U})$

Proof: (i) $\Rightarrow$ (ii) Let $x \in X$. If $y \in X$ is such that $y \neq x$ there exists disjoint rgwalc-open sets $U$ and $V$ such that $x \in U$ and $y \in V$. Then $x \in U \subset X-V$ which implies $X-V$ is rgw $\alpha$ lc- open and $y \notin X-V$. Therefore $y \notin \operatorname{rgw} \alpha \mathrm{lc}-\mathrm{cl}(\mathrm{U})$.

(ii) $\Rightarrow$ (i) Let $\mathrm{x}, \mathrm{y} \in \mathrm{X}$ and $\mathrm{x} \neq \mathrm{y}$. By (ii), there exists a rgwalc- open $\mathrm{U}$ containing $\mathrm{x}$ such that $\mathrm{y} \notin \operatorname{rgw} \alpha \mathrm{lc}-\mathrm{cl}(\mathrm{U})$. Therefore $\mathrm{y} \in \mathrm{X}-(\operatorname{rgw} \alpha \mathrm{lc}-\mathrm{cl}(\mathrm{U}))$. $\mathrm{X}-(\operatorname{rgw} \alpha \mathrm{lc}-\mathrm{cl}(\mathrm{U}))$ is $\operatorname{rgw} \alpha \mathrm{lc}-\mathrm{open}$ and $\mathrm{x} \notin \mathrm{X}-(\operatorname{rgw} \alpha \mathrm{lc}-\mathrm{cl}(\mathrm{U}))$. Also $\mathrm{U} \cap \mathrm{X}-$ $(\operatorname{rgw} \alpha \mathrm{lc}-\mathrm{cl}(\mathrm{U}))=\Phi$. Hence $(\mathrm{X}, \tau)$ is rgw $\alpha \mathrm{lc}-\tau_{2}$ space.

\section{rgwalc- Regular Space:-}

In this section, we introduce a new class of spaces called rgwalc-regular spaces using rgwolc-closed sets and obtain some of their characterizations.

Definition 4.1: A topological space $X$ is said to be rgwalc-regular if for each rgw $\alpha$ lc-closed set $F$ and a point $x \notin F$, there exist disjoint open sets $\mathrm{G}$ and $\mathrm{H}$ such that $\mathrm{F} \subseteq \mathrm{G}$ and $\mathrm{x} \in \mathrm{H}$.

We have the following interrelationship between rgwalc-regularity and regularity.

Theorem 4.2: Every rgwalc-regular space is regular.

Proof: Let $\mathrm{X}$ be a rgwalc-regular space. Let $\mathrm{F}$ be any closed set in $\mathrm{X}$ and a point $\mathrm{x} \in \mathrm{X}$ such that $\mathrm{x} \notin \mathrm{F}$. By [2], $\mathrm{F}$ is rgwalc-closed and $\mathrm{x} \notin \mathrm{F}$. Since $\mathrm{X}$ is a rgw $\alpha$ lc-regular space, there exists a pair of disjoint open sets $\mathrm{G}$ and $\mathrm{H}$ such that $\mathrm{F} \subseteq \mathrm{G}$ and $\mathrm{x} \in \mathrm{H}$. Hence $\mathrm{X}$ is a regular space.

Theorem 4.3: If $X$ is a regular space and $\tau \operatorname{rgw} \alpha-$ space, then $X$ is rgw $\alpha$ lc- regular.

Proof: Let $\mathrm{X}$ be a regular space and $\tau \operatorname{rgw} \alpha$ - space. Let $\mathrm{F}$ be any $\operatorname{rgw} \alpha \mathrm{lc}$-closed set in $\mathrm{X}$ and a point $\mathrm{x} \in \mathrm{X}$ such that $\mathrm{x} \notin \mathrm{F}$. Since $X$ is $\tau \mathrm{rgw} \alpha-$ space, $F$ is closed and $\mathrm{x} \notin \mathrm{F}$. Since $X$ is a regular space, there exists a pair of disjoint open sets $\mathrm{G}$ and $\mathrm{H}$ such that $\mathrm{F} \subseteq \mathrm{G}$ and $\mathrm{x} \in \mathrm{H}$. Hence $\mathrm{X}$ is a rgwalc-regular space

Theorem 4.4: Every rgw $\alpha$ lc-regular space is $\alpha$-regular.

Proof: Let $X$ be a rgwalc -regular space. Let $F$ be any $\alpha$-closed set in $X$ and a point $x \in X$ such that $x \notin F$. By [2], $F$ is rgwalc-closed and $\mathrm{x} \notin \mathrm{F}$. Since $X$ is a rgwalc-regular space, there exists a pair of disjoint open sets $\mathrm{G}$ and $\mathrm{H}$ such that $\mathrm{F} \subseteq \mathrm{G}$ and $\mathrm{x} \in \mathrm{H}$. Hence $\mathrm{X}$ is a $\alpha$ - regular space.

We have the following characterization.

Theorem 4.5: The following statements are equivalent for a topological space $X$

i) $\mathrm{X}$ is a rgw $\alpha$ lc-regular space.

ii) For each $\mathrm{x} \in \mathrm{X}$ and each $\operatorname{rgw} \alpha \mathrm{lc}$ open neighbourhood $\mathrm{U}$ of $\mathrm{x}$ there exists an open neighbourhood $\mathrm{N}$ of $\mathrm{x}$ such that $\mathrm{cl}(\mathrm{N}) \subseteq \mathrm{U}$.

Proof: (i) $\Rightarrow>$ (ii): Suppose $\mathrm{X}$ is a rgwalc - regular space. Let $\mathrm{U}$ be any rgwalc -

neighbourhood of $x$. Then there exists rgwalc -open set $G$ such that $x \in G \subseteq U$. Now $X$

$-G$ is rgwalc -closed set and $\mathrm{x} \notin X-G$. Since $X$ is rgwalc -regular, there exist open sets $M$ and $N$ such that $X-G$ $\subseteq \mathrm{M}, \mathrm{x} \in \mathrm{N}$ and $\mathrm{M} \cap \mathrm{N}=\phi$ and so $\mathrm{N} \subseteq \mathrm{X}-\mathrm{M}$. Now $\operatorname{cl}(\mathrm{N}) \subseteq \mathrm{cl}(\mathrm{X}-\mathrm{M})=\mathrm{X}-\mathrm{M}$ and $\mathrm{X}-\mathrm{G} \subseteq \mathrm{M}$. This implies $\mathrm{X}-\mathrm{M}$ $\subseteq \mathrm{G} \subseteq \mathrm{U}$. Therefore $\mathrm{cl}(\mathrm{N}) \subseteq \mathrm{U}$.

(ii) $\Rightarrow>$ (i): Let $F$ be any rgwalc- closed set in $X$ and $x \notin F$ or $x \in X-F$ and $X-F$ is a rgwalc-open and so $X-F$ is a rgwalc - neighbourhood of $\mathrm{x}$. By hypothesis, there exists an open neighbourhood $\mathrm{N}$ of $\mathrm{x}$ such that $\mathrm{x} \in \mathrm{N}$ and $\operatorname{cl}(\mathrm{N}) \subseteq$ $\mathrm{X}-\mathrm{F}$. This implies $\mathrm{F} \subseteq \mathrm{X}-\mathrm{cl}(\mathrm{N})$ is an open set containing $\mathrm{F}$ and $\mathrm{N} \cap\{(\mathrm{X}-\mathrm{cl}(\mathrm{N})\}=\phi$. Hence $\mathrm{X}$ is rgwalc - regular space.

We have another characterization of rgw $\alpha$ lc - regularity in the following.

Theorem 4.6: A topological space $X$ is rgwalc-regular if and only if for each rgwalc-closed set $F$ of $X$ and each $x \in X-F$ there exist open sets $G$ and $H$ of $X$ such that $x \in G, F \subseteq H$ and $\operatorname{cl}(G) \cap \operatorname{cl}(H)=\phi$.

Proof: Suppose $\mathrm{X}$ is rgwalc - regular space. Let $\mathrm{F}$ be a rgwalc -closed set in $\mathrm{X}$ with $\mathrm{x} \notin \mathrm{F}$. Then there exists open sets $\mathrm{M}$ and $\mathrm{H}$ of $\mathrm{X}$ such that $\mathrm{x} \in \mathrm{M}, \mathrm{F} \subseteq \mathrm{H}$ and $\mathrm{M} \cap \mathrm{H}=\phi$. This implies $\mathrm{M} \cap \mathrm{cl}(\mathrm{H})=\phi$. As $\mathrm{X}$ is rgwalc -regular, 
there exist open sets $\mathrm{U}$ and $\mathrm{V}$ such that $\mathrm{x} \in \mathrm{U}, \operatorname{cl}(\mathrm{H}) \subseteq \mathrm{V}$ and $\mathrm{U} \cap \mathrm{V}=\Phi$, so $\operatorname{cl}(\mathrm{U}) \cap \mathrm{V}=\Phi$. Let $\mathrm{G}=\mathrm{M} \cap \mathrm{U}$, then $\mathrm{G}$ and $\mathrm{H}$ are open sets of $\mathrm{X}$ such that $\mathrm{x} \in \mathrm{G}, \mathrm{F} \subseteq \mathrm{H}$ and $\mathrm{cl}(\mathrm{H}) \cap \mathrm{cl}(\mathrm{H})=\phi$.

Conversely, if for each rgwalc - closed set $\mathrm{F}$ of $\mathrm{X}$ and each $\mathrm{x} \in \mathrm{X}-\mathrm{F}$ there exists open sets

$\mathrm{G}$ and $\mathrm{H}$ such that $\mathrm{x} \in \mathrm{G}, \mathrm{F} \subseteq \mathrm{H}$ and $\mathrm{cl}(\mathrm{H}) \cap \mathrm{cl}(\mathrm{H})=\Phi$. This implies $\mathrm{x} \in \mathrm{G}, \mathrm{F} \subseteq \mathrm{H}$ and $\mathrm{G} \cap \mathrm{H}=\phi$. Hence $\mathrm{X}$ is rgwalc - regular.

Now we prove that rgwalc-regularity is a hereditary property.

Theorem 4.7: Every subspace of a rgwalc- regular space is rgwalc-regular.

Proof: Let $\mathrm{X}$ be a rgwalc -regular space. Let $\mathrm{Y}$ be a subspace of $\mathrm{X}$. Let $\mathrm{x} \in \mathrm{Y}$ and $\mathrm{F}$ be a rgwalc- closed set in $\mathrm{Y}$ such that $\mathrm{x} \notin \mathrm{F}$. Then there is a closed set and so rgw $\alpha$ lc -closed set $\mathrm{A}$ of $\mathrm{X}$ with $\mathrm{F}=\mathrm{Y} \cap \mathrm{A}$ and $\mathrm{x} \notin \mathrm{A}$. Therefore we have $\mathrm{x} \in \mathrm{X}, \mathrm{A}$ is rgwalc-closed in $\mathrm{X}$ such that $\mathrm{x} \notin \mathrm{A}$. Since $\mathrm{X}$ is rgwalc-regular, there exist open sets $\mathrm{G}$ and $\mathrm{H}$ such that $x \in G, A \subseteq H$ and $G \cap H=\Phi$. Note that $Y \cap G$ and $Y \cap H$ are open sets in $Y$. Also $x \in G$ and $x \in Y$, which implies $\mathrm{x} \in \mathrm{Y} \cap \mathrm{G}$ and $\mathrm{A} \subseteq \mathrm{H}$ implies $\mathrm{Y} \cap \mathrm{A} \subseteq \mathrm{Y} \cap \mathrm{H}, \mathrm{F} \subseteq \mathrm{Y} \cap \mathrm{H}$. Also $(\mathrm{Y} \cap \mathrm{G}) \cap(\mathrm{Y} \cap \mathrm{H})=\Phi$. Hence $\mathrm{Y}$ is rgwalcregular space.

We have yet another characterization of rgwalc-regularity in the following.

Theorem 4.8: The following statements about a topological space $\mathrm{X}$ are equivalent:

(i) $\mathrm{X}$ is rgwalc-regular

(ii) For each $\mathrm{x} \in \mathrm{X}$ and each rgwalc-open set $\mathrm{U}$ in $\mathrm{X}$ such that $\mathrm{x} \in \mathrm{U}$ there exists an open set $\mathrm{V}$ in $\mathrm{X}$ such that $\mathrm{x} \in \mathrm{V} \subseteq$ $\mathrm{cl}(\mathrm{V}) \subseteq \mathrm{U}$

(iii) For each point $\mathrm{x} \in \mathrm{X}$ and for each $\operatorname{rgw} \alpha$ lc-closed set $\mathrm{A}$ with $\mathrm{x} \notin \mathrm{A}$, there exists an open set $\mathrm{V}$ containing $\mathrm{x}$ such that $\mathrm{cl}(\mathrm{V}) \cap \mathrm{A}=\Phi$.

Proof: (i) $=>$ (ii): Follows from Theorem 3.5.

(ii) $\Rightarrow>$ (iii): Suppose (ii) holds. Let $\mathrm{x} \in \mathrm{X}$ and $\mathrm{A}$ be an rgwalc- closed set of $\mathrm{X}$ such that $\mathrm{x} \notin \mathrm{A}$. Then $\mathrm{X}-\mathrm{A}$ is a rgwalc-open set with $\mathrm{x} \in \mathrm{X}-\mathrm{A}$. By hypothesis, there exists an open set $\mathrm{V}$ such that $\mathrm{x} \in \mathrm{V} \subseteq \operatorname{cl}(\mathrm{V}) \subseteq \mathrm{X}-\mathrm{A}$. That is $\mathrm{x} \in \mathrm{V}, \mathrm{V} \subseteq \operatorname{cl}(\mathrm{A})$ and $\operatorname{cl}(\mathrm{A}) \subseteq \mathrm{X}-\mathrm{A}$. So $\mathrm{x} \in \mathrm{V}$ and $\mathrm{cl}(\mathrm{V}) \cap \mathrm{A}=\Phi$.

(iii) $\Rightarrow$ (ii): Let $x \in X$ and $U$ be an $\operatorname{rgw} \alpha$ lc-open set in $X$ such that $x \in U$. Then $X-U$ is an rgwalc -closed set and $\mathrm{x} \in \mathrm{X}-\mathrm{U}$. Then by hypothesis, there exists an open set $\mathrm{V}$ containing $\mathrm{x}$ such that $\mathrm{cl}(\mathrm{V}) \cap(\mathrm{X}-\mathrm{U})=\Phi$. Therefore $\mathrm{x} \in \mathrm{V}$, $\mathrm{cl}(\mathrm{V}) \subseteq \mathrm{U}$ so $\mathrm{x} \in \mathrm{V} \subseteq \mathrm{cl}(\mathrm{V}) \subseteq \mathrm{U}$.

The invariance of rgwalc- regularity is given in the following.

Theorem 4.9: Let $\mathrm{f}: \mathrm{X} \rightarrow \mathrm{Y}$ be a bijective, rgwalc -irresolute and open map from a rgwalc- regular space $\mathrm{X}$ into a topological space $Y$, then $Y$ is rgwalc-regular.

Proof: Let $y \in Y$ and $F$ be a rgw $\alpha$ lc-closed set in $Y$ with $y \notin F$. Since $f$ is rgw $\alpha$ lc-irresolute, $f^{-1}(F)$ is rgw $\alpha$ lc-closed set in $X$. Let $f(x)=y$ so that $x=f^{-1}(y)$ and $x \notin f^{-1}(F)$. Again $X$ is rgw $\alpha$ lc-regular space, there exist open sets $U$ and $V$ such that $x \in U$ and $f^{-1}(F) \subseteq G, U \cap V=\Phi$. Since $f$ is open and bijective, we have $y \in f(U), F \subseteq f(V)$ and $f(U) \cap f(V$ )$=\mathrm{f}(\mathrm{U} \cap \mathrm{V})=\mathrm{f}(\Phi)=\Phi$. Hence $\mathrm{Y}$ is rgw $\alpha \mathrm{lc}-$ regular space.

Theorem 4.10: Let $\mathrm{f}: \mathrm{X} \rightarrow \mathrm{Y}$ be a bijective, rgw $\alpha$ lc -closed map from a topological space $\mathrm{X}$ into a rgw $\alpha$ lc-regular space $Y$. If $X$ is $\tau \operatorname{rgw} \alpha-$-space, then $X$ is rgwalc-regular.

Proof: Let $\mathrm{x} \in \mathrm{X}$ and $\mathrm{F}$ be an rgw $\alpha$ lc-closed set in $\mathrm{X}$ with $\mathrm{x} \notin \mathrm{F}$. Since $\mathrm{X}$ is $\tau \operatorname{rgw} \alpha-$ space, $F$ is closed in $\mathrm{X}$. Then $\mathrm{f}(\mathrm{F})$ is rgwalc-closed set with $\mathrm{f}(\mathrm{x}) \notin \mathrm{f}(\mathrm{F})$ in $\mathrm{Y}$, since $\mathrm{f}$ is rgw $\alpha \mathrm{lc}$-closed. As $\mathrm{Y}$ is rgw $\alpha$ lc-regular, there exist disjoint open sets $\mathrm{U}$ and $\mathrm{V}$ such that $\mathrm{f}(\mathrm{x}) \in \mathrm{U}$ and $\mathrm{f}(\mathrm{F}) \subseteq \mathrm{V}$. Therefore $\mathrm{x} \in \mathrm{f}^{-1}(\mathrm{U})$ and $\mathrm{F} \subseteq \mathrm{f}^{-1}(\mathrm{~V})$. Hence $\mathrm{X}$ is rgwalc-regular space.

Theorem 4.11: Let $X$ be a topological space. If $X$ is a rgwalc-regular and a $\tau_{1}$ space then $X$ is an rgw $\alpha$ lc- $\tau_{2}$ space. Proof: Suppose $\mathrm{x}, \mathrm{y} X$ such that $\mathrm{x} \neq \mathrm{y}$. Since $\mathrm{X}$ is $\tau_{1}$ - space then there is an open set $\mathrm{U}$ such that $\mathrm{x} \in \mathrm{U}, \mathrm{y} \notin \mathrm{U}$. Since $\mathrm{X}$ is rgwalc-regular space and $\mathrm{U}$ is an open set which contains $\mathrm{x}$, then there is rgwalc-open set $\mathrm{V}$ such that $\mathrm{x} \in \mathrm{V} \subset \operatorname{rgw} \alpha \mathrm{lc}-\mathrm{cl}(\mathrm{V}) \subseteq \mathrm{U}$. Since y $\mathrm{U}$, hence $\mathrm{y} \operatorname{rgw} \alpha \mathrm{lc}-\mathrm{cl}(\mathrm{V})$. Therefore $\mathrm{y} \in \mathrm{X}-(\operatorname{rgw} \alpha \mathrm{lc}-\mathrm{cl}(\mathrm{V}))$. Hence there are $\operatorname{rgw} \alpha \mathrm{lc}-$ open sets $\mathrm{V}$ and $\mathrm{X}-(\operatorname{rgw} \alpha \mathrm{lc}-\mathrm{cl}(\mathrm{V}))$ such that $(\mathrm{X}-(\operatorname{rgw} \alpha \mathrm{lc}-\mathrm{cl}(\mathrm{V}))) \cap \mathrm{V}=\Phi$. Hence $\mathrm{X}$ is rgwalc- $\tau_{2}$ space.

rgw $\alpha$ lc-Normal Spaces;-

In this section, we introduce the concept of rgw $\alpha$ lc- normal spaces and study some of their characterizations.

Definition 5.1: A topological space $X$ is said to be rgwalc-normal if for each pair of disjoint rgwolc- closed sets A and $\mathrm{B}$ in $\mathrm{X}$, there exists a pair of disjoint open sets $\mathrm{U}$ and $\mathrm{V}$ in $\mathrm{X}$ such that $\mathrm{A} \subseteq \mathrm{U}$ and $\mathrm{B} \subseteq \mathrm{V}$.

We have the following interrelationship. 
Theorem 5.2: Every rgw $\alpha$ lc-normal space is normal.

Proof: Let X be a rgwalc-normal space. Let A and B be a pair of disjoint closed sets in X. From [2], A and B are rgwalc-closed sets in X. Since X is rgwalc-normal, there exists a pair of disjoint open sets $\mathrm{G}$ and $\mathrm{H}$ in $\mathrm{X}$ such that $\mathrm{A} \subseteq \mathrm{G}$ and $\mathrm{B} \subseteq \mathrm{H}$. Hence $\mathrm{X}$ is normal.

Remark 5.3: The converse need not be true in general as seen from the following example.

Example 5.4: Let Let $X=\{a, b, c\}, \tau=\{X, \phi,\{a\},\{b\},\{a, b\}\}$. Then the space $X$ is normal but not rgwalc - normal, since the pair of disjoint rgw $\alpha$ lc-closed sets namely, $A=\{b\}$ and $B=\{c\}$ for which there do not exists disjoint open sets $\mathrm{G}$ and $\mathrm{H}$ such that $\mathrm{A} \subseteq \mathrm{G}$ and $\mathrm{B} \subseteq \mathrm{H}$.

Theorem 5.5: If $\mathrm{X}$ is normal and $\tau \operatorname{rgw} \alpha-$ space, then $\mathrm{X}$ is rgw $\alpha$ lc-normal.

Proof: Let X be a normal space. Let A and B be a pair of disjoint rgw $\alpha$ lc-closed sets in X. since $\tau$ rgw $\alpha$-space, A and $B$ are closed sets in $X$. Since $X$ is normal, there exists a pair of disjoint open sets $G$ and $H$ in $X$ such that $A \subseteq G$ and $\mathrm{B} \subseteq \mathrm{H}$. Hence $\mathrm{X}$ is rgwalc- normal.

Theorem 5.6: Every rgw $\alpha$ lc-normal space is $\mathrm{w}-$ normal.

Proof: Let X be a rgwalc-normal space. Let A and B be a pair of disjoint w-closed sets in X. From [2], A and B are rgwalc-closed sets in X. Since X is rgwalc-normal, there exists a pair of disjoint open sets $\mathrm{G}$ and $\mathrm{H}$ in $\mathrm{X}$ such that $\mathrm{A}$ $\subseteq \mathrm{G}$ and $\mathrm{B} \subseteq \mathrm{H}$. Hence $\mathrm{X}$ is $\mathrm{w}-$ normal.

Hereditary property of rgw $\alpha$ lc-normality is given in the following.

Theorem 5.7: A rgw $\alpha$ lc-closed subspace of a rgw $\alpha$ lc-normal space is rgw $\alpha$ lc-normal.

Proof: Let X a be rgwalc-normal space. Let $\mathrm{Y}$ be a rgwalc-closed subspace of X. Let A and B be pair of disjoint rgwalc-closed sets in Y. Then A and B be pair of disjoint rgwolc-closed sets in X. Since X is rgwolc-normal, there exist disjoint open sets $G$ and $H$ in $X$ such that $A \subseteq G$ and $B \subseteq H$. Since $G$ and $H$ are open in $X, Y \cap G$ and $Y$ $\cap \mathrm{H}$ are open in $\mathrm{Y}$. Also we have $\mathrm{A} \subseteq \mathrm{G}$ and $\mathrm{B} \subseteq \mathrm{H}$ implies $\mathrm{Y} \cap \mathrm{A} \subseteq \mathrm{Y} \cap \mathrm{G}, \mathrm{Y} \cap \mathrm{B} \subseteq \mathrm{Y} \cap \mathrm{H}$. So $\mathrm{A} \subseteq \mathrm{Y} \cap \mathrm{G}$ and $\mathrm{B} \subseteq \mathrm{Y} \cap \mathrm{H}$ and $(\mathrm{Y} \cap \mathrm{G}) \cap(\mathrm{Y} \cap \mathrm{H})=\mathrm{Y} \cap(\mathrm{G} \cap \mathrm{H})=\phi$. Hence $\mathrm{Y}$ is rgwalc -normal.

We have the following characterization.

Theorem 5.8: The following statements for a topological space $X$ are equivalent:

i) $\mathrm{X}$ is rgwalc-normal.

ii) For each rgwalc-closed set $\mathrm{A}$ and each rgwalc-open set $\mathrm{U}$ such that $\mathrm{A} \subseteq \mathrm{U}$, there exists an open set $\mathrm{V}$ such that $\mathrm{A} \subseteq \mathrm{V} \subseteq \mathrm{cl}(\mathrm{V}) \subseteq \mathrm{U}$

iii) For any disjoint rgw $\alpha$ lc-closed sets $\mathrm{A}, \mathrm{B}$, there exists an open set $\mathrm{V}$ such that $\mathrm{A} \subseteq \mathrm{V}$ and $\mathrm{cl}(\mathrm{V}) \cap \mathrm{B}=\Phi$

iv) For each pair A, B of disjoint rgwalc-closed sets there exist open sets $\mathrm{U}$ and $\mathrm{V}$ such that $\mathrm{A} \subseteq \mathrm{U}, \mathrm{B} \subseteq \mathrm{V}$ and $\operatorname{cl}(\mathrm{U}) \cap \operatorname{cl}(\mathrm{V})=\Phi$.

Proof: (i) $\Rightarrow>$ (ii): Let A be a rgwalc-closed set and U be a rgwalc-open set such that $\mathrm{A} \subseteq \mathrm{U}$. Then $\mathrm{A}$ and $\mathrm{X}-\mathrm{U}$ are disjoint rgwalc-closed sets in $\mathrm{X}$. Since $\mathrm{X}$ is rgwalc-normal, there exists a pair of disjoint open sets $\mathrm{V}$ and $\mathrm{W}$ in $\mathrm{X}$ such that $\mathrm{A} \subseteq \mathrm{V}$ and $\mathrm{X}-\mathrm{U} \subseteq \mathrm{W}$. Now $\mathrm{X}-\mathrm{W} \subseteq \mathrm{X}-(\mathrm{X}-\mathrm{U})$, so $\mathrm{X}-\mathrm{W} \subseteq \mathrm{U}$ also $\mathrm{V} \cap \mathrm{W}=\Phi$ implies $\mathrm{V} \subseteq \mathrm{X}-\mathrm{W}$, so cl $(\mathrm{V}) \subseteq \operatorname{cl}(\mathrm{X}-\mathrm{W})$ which implies $\mathrm{cl}(\mathrm{V}) \subseteq \mathrm{X}-\mathrm{W}$. Therefore $\mathrm{cl}(\mathrm{V}) \subseteq \mathrm{X}-\mathrm{W} \subseteq \mathrm{U}$. So cl $(\mathrm{V}) \subseteq \mathrm{U}$. Hence $\mathrm{A} \subseteq \mathrm{V} \subseteq$ $\mathrm{cl}(\mathrm{V}) \subseteq \mathrm{U}$.

(ii) $=>$ (iii): Let $A$ and $B$ be a pair of disjoint rgwalc- closed sets in $X$. Now $A \cap B=\Phi$, so $A \subseteq X-B$, where $A$ is rgwolc-closed and $\mathrm{X}-\mathrm{B}$ is rgwalc-open. Then by (ii) there exists an open set $\mathrm{V}$ such that $\mathrm{A} \subseteq \mathrm{V} \subseteq \mathrm{cl}(\mathrm{V}) \subseteq \mathrm{X}-\mathrm{B}$. Now $\mathrm{cl}(\mathrm{V}) \subseteq \mathrm{X}-\mathrm{B}$ implies $\mathrm{cl}(\mathrm{V}) \cap \mathrm{B}=\Phi$. Thus $\mathrm{A} \subseteq \mathrm{V}$ and $\mathrm{cl}(\mathrm{V}) \cap \mathrm{B}=\Phi$

(iii) $=>$ (iv): Let A and B be a pair of disjoint rgwalc-closed sets in $\mathrm{X}$. Then from (iii) there exists an open set $\mathrm{U}$ such that $\mathrm{A} \subseteq \mathrm{U}$ and $\operatorname{cl}(\mathrm{U}) \cap \mathrm{B}=\Phi$. Since $\operatorname{cl}(\mathrm{V})$ is closed, so rgwalc-closed set. Therefore $\mathrm{cl}(\mathrm{V})$ and $\mathrm{B}$ are disjoint rgw $\alpha$ lc-closed sets in X. By hypothesis, there exists an open set $\mathrm{V}$, such that $\mathrm{B} \subseteq \mathrm{V}$ and $\operatorname{cl}(\mathrm{U}) \cap \operatorname{cl}(\mathrm{V})=\Phi$.

(iv) $\Rightarrow$ (i): Let $A$ and $B$ be a pair of disjoint rgwalc-closed sets in $X$. Then from (iv) there exist an open sets $U$ and $\mathrm{V}$ in $\mathrm{X}$ such that $\mathrm{A} \subseteq \mathrm{U}, \mathrm{B} \subseteq \mathrm{V}$ and $\operatorname{cl}(\mathrm{U}) \cap \mathrm{cl}(\mathrm{V})=\Phi$. So $\mathrm{A} \subseteq \mathrm{U}, \mathrm{B} \subseteq \mathrm{V}$ and $\mathrm{U} \cap \mathrm{V}=\Phi$. Hence $\mathrm{X}$ rgw $\alpha \mathrm{cc}-$ normal.

Theorem 5.9: Let $X$ be a topological space. Then $X$ is rgwalc-normal if and only if for any pair $A, B$ of disjoint rgwalc-closed sets there exist open sets $\mathrm{U}$ and $\mathrm{V}$ of $\mathrm{X}$ such that $\mathrm{A} \subseteq \mathrm{U}, \mathrm{B} \subseteq \mathrm{V}$ and $\operatorname{cl}(\mathrm{U}) \cap \mathrm{cl}(\mathrm{V})=\Phi$.

Proof: Follows from Theorem 5.8. 
Theorem 5.10: Let $X$ be a topological space. Then the following are equivalent:

(i) $\mathrm{X}$ is normal

(ii) For any disjoint closed sets $\mathrm{A}$ and $\mathrm{B}$, there exist disjoint rgwalc-open sets $\mathrm{U}$ and $\mathrm{V}$ such that $\mathrm{A} \subseteq \mathrm{U}, \mathrm{B} \subseteq \mathrm{V}$.

(iii) For any closed set $\mathrm{A}$ and any open set $\mathrm{V}$ such that $\mathrm{A} \subseteq \mathrm{V}$, there exists an rgwalc-open set $\mathrm{U}$ of $\mathrm{X}$ such that $\mathrm{A}$ $\subseteq \mathrm{U} \subseteq \operatorname{r\alpha cl}(\mathrm{U}) \subseteq \mathrm{V}$.

Proof: (i) =>(ii): Suppose $\mathrm{X}$ is normal. Since every open set is rgwalc-open [2], (ii) follows.

(ii) $=>$ (iii): Suppose (ii) holds. Let $\mathrm{A}$ be a closed set and $\mathrm{V}$ be an open set containing $\mathrm{A}$. Then $\mathrm{A}$ and $\mathrm{X}-\mathrm{V}$ are disjoint closed sets. By (ii), there exist disjoint rgwalc-open sets $\mathrm{U}$ and $\mathrm{W}$ such that $\mathrm{A} \subseteq \mathrm{U}$ and $\mathrm{X}-\mathrm{V} \subseteq \mathrm{W}$, since $\mathrm{X}$ $-\mathrm{V}$ is closed, so rgwalc-closed. From Theorem 2.3.14 [2], we have $\mathrm{X}-\mathrm{V} \subseteq \operatorname{r\alpha int}(\mathrm{W})$ and $\mathrm{U} \cap \operatorname{r\alpha int}(\mathrm{W})=\Phi$ and so we have $\mathrm{cl}(\mathrm{U}) \cap \operatorname{raint}(\mathrm{W})=\Phi$. Hence $\mathrm{A} \subseteq \mathrm{U} \subseteq \operatorname{r\alpha cl}(\mathrm{U}) \subseteq \mathrm{X}-\operatorname{r\alpha int}(\mathrm{W}) \subseteq \mathrm{V}$. Thus $\mathrm{A} \subseteq \mathrm{U} \subseteq \operatorname{r\alpha cl}(\mathrm{U}) \subseteq \mathrm{V}$.

(iii) $=>$ (i): Let $\mathrm{A}$ and $\mathrm{B}$ be a pair of disjoint closed sets of $\mathrm{X}$. Then $\mathrm{A} \subseteq \mathrm{X}-\mathrm{B}$ and $\mathrm{X}-\mathrm{B}$ is open. There exists a rgwalc-open set $\mathrm{G}$ of $\mathrm{X}$ such that $\mathrm{A} \subseteq \mathrm{G} \subseteq \operatorname{r\alpha cl}(\mathrm{G}) \subseteq \mathrm{X}-\mathrm{B}$. Since $\mathrm{A}$ is closed, it is rgwalc-closed, we have $\mathrm{A} \subseteq$ $\operatorname{int}(\mathrm{G})$. Take $\mathrm{U}=\operatorname{int}(\mathrm{cl}(\operatorname{int}(\operatorname{raint}(\mathrm{G}))))$ and $\mathrm{V}=\operatorname{int}(\operatorname{cl}(\operatorname{int}(\mathrm{X} \operatorname{racl}(\mathrm{G}))))$. Then $\mathrm{U}$ and $\mathrm{V}$ are disjoint open sets of $\mathrm{X}$ such that $\mathrm{A} \subseteq \mathrm{U}$ and $\mathrm{B} \subseteq \mathrm{V}$. Hence $\mathrm{X}$ is normal.

Theorem 5.11: If $\mathrm{f}: \mathrm{X} \rightarrow \mathrm{Y}$ is bijective, open, rgwalc-irresolute from a rgwalc-normal space $\mathrm{X}$ onto $\mathrm{Y}$ then is rgwalc-normal.

Proof: Let A and B be disjoint rgwalc-closed sets in $Y$. Then $\mathrm{f}^{-1}(\mathrm{~A})$ and $\mathrm{f}^{-1}(\mathrm{~B})$ are disjoint rgwalc -closed sets in $\mathrm{X}$ as $\mathrm{f}$ is rgwolc-irresolute. Since $\mathrm{X}$ is rgwolc-normal, there exist disjoint open sets $\mathrm{G}$ and $\mathrm{H}$ in $\mathrm{X}$ such that $\mathrm{f}^{-1}(\mathrm{~A})$ $\subseteq \mathrm{G}$ and $\mathrm{f}^{-1}(\mathrm{~B}) \subseteq \mathrm{H}$. As $\mathrm{f}$ is bijective and open, $\mathrm{f}(\mathrm{G})$ and $\mathrm{f}(\mathrm{H})$ are disjoint open sets in $\mathrm{Y}$ such that $\mathrm{A} \subseteq \mathrm{f}(\mathrm{G})$ and $\mathrm{B}$ $\subseteq \mathrm{f}(\mathrm{H})$. Hence $\mathrm{Y}$ is rgw $\alpha$ lc-normal.

\section{References:-}

1. B.M. Munshi, Separation axioms, Acta Ciencia Indica 12 (1986) 140-146.

2. C. Dorsett, Semi normal Spaces, Kyungpook Math. J. 25 (1985) 173-180.

3. M.S. John, A Study on Generalizations of Closed Sets and Continuous Maps in Topological and Bitopological spaces , Ph.D. Thesis, Bharathiar University, Coimbatore (2002).

4. N. Levine, Generalized Closed sets in Topology, Rendi. Circ. Math. Palermo 19/2 (1970) 89-96.

5. R. S. Wali, Vijayalaxmi R. Patil On rgw $\alpha$-Locally closed sets in Topological Spaces (processing).

6. R. S. Wali, Vijayalaxmi R. Patil On RGW $\alpha$ LC-continuous and RGW $\alpha$ LC-irresolute maps in Topological Spaces (processing).

7. S.N. Maheshwar and R. Prasad, On s-normal spaces, Bull. Math. Soc. Sci. Math. R.S. Roumanie 22 (1978) 2728.

8. S.P. Arya and T.M. Nour, Characterization of $s-$ normal spaces, Indian. J.Pure and Appl. Math., 21(8),(1990), 717-719.

9. S.S. Benchalli, T.D. Rayanagoudar and P.G. Patil, $g^{*}-$ Pre Regular and $g^{*}-$ Pre Normal Spaces, Int. Math. Forum 4/48(2010) 2399-2408.

10. T. Noiri and V. Popa, On g-regular spaces and some functions, Mem. Fac. Sci. Kochi Univ. Math 20 (1999)67-74.

11. Thakur C.K Raman, Vidyottama Kumari and M.K. Sharma, $\alpha$-Generalized \& $\alpha^{*}$ - separation Axioms for Topological Spaces, IOSR-JM, Volume 10, Issue 3 Ver. VI(2014), PP 32-36. 